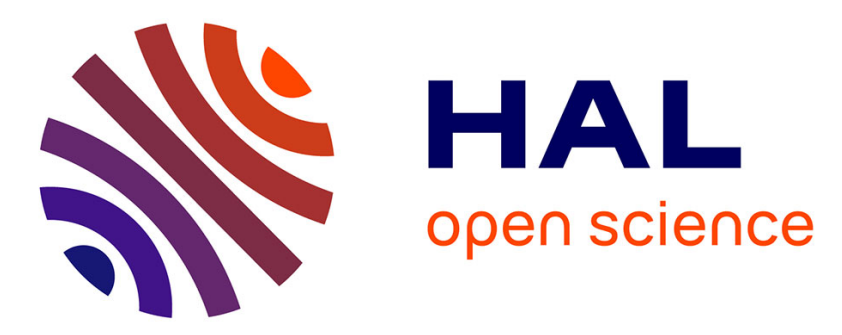

\title{
Networks as culture: understanding and accounting for risks within networks of medico-social actors
}

Sophie Arborio, Jenna Strzykala, Anne-Marie Toniolo, Hélène Deforge, Lynda Lotte, Jean-Michel Hascoët

\section{- To cite this version:}

Sophie Arborio, Jenna Strzykala, Anne-Marie Toniolo, Hélène Deforge, Lynda Lotte, et al.. Networks as culture: understanding and accounting for risks within networks of medico-social actors. Anthropology and Medicine, 2020, 27 (1), pp.64-79. 10.1080/13648470.2019.1641013 . hal-02949821

\section{HAL Id: hal-02949821 \\ https://hal.science/hal-02949821}

Submitted on 26 Sep 2020

HAL is a multi-disciplinary open access archive for the deposit and dissemination of scientific research documents, whether they are published or not. The documents may come from teaching and research institutions in France or abroad, or from public or private research centers.
L'archive ouverte pluridisciplinaire HAL, est destinée au dépôt et à la diffusion de documents scientifiques de niveau recherche, publiés ou non, émanant des établissements d'enseignement et de recherche français ou étrangers, des laboratoires publics ou privés. 


\title{
Networks as Culture:
}

\section{Understanding and accounting for risks within networks of medico-social actors}

\author{
S. Arborio ${ }^{\text {a }}$ J. Strzykala ${ }^{\text {b; }}$ A.M. Toniolo ${ }^{\text {c }}$ H. Deforge ${ }^{\text {d }}$ L. Lotte ${ }^{\text {e }}$ J.M Hascoët ${ }^{\mathrm{f}}$
}

a. corresponding author

associate professor, CREM research unit, University of Lorraine

UFR STAPS

30 rue du jardin botanique

54600 Villers-lès-Nancy (France)

sophie.arborio@univ-lorraine.fr

b. research assistant, Maison des Sciences de l'Homme

91 avenue de la Libération

54001 Nancy (France) ${ }^{1}$

c. professor, Interpsy research unit, University of Lorraine

Campus Lettres et Sciences Humaines et Sociales

23 boulevard Albert 1er

54015 Nancy (France)

d. psychologist, Interpsy research unit, University of Lorraine

Campus Lettres et Sciences Humaines et Sociales

23 boulevard Albert 1er

54015 Nancy (France)

e. research engineer, CERMES3 research unit, University Paris Descartes

Campus CNRS

7 rue Guy Môquet

94801 Villejuif (France)

f. professor and hospital practitioner, University clinic Nancy (maternity unit)

10 rue du Docteur Heydenreich

54042 Nancy (France)

All authors declare that there is no conflict of interest relating to this work.

This multi-sited research was carried out throughout the Lorraine region of France and was affiliated to the CREM Research unit (University of Lorraine) during data collection and analysis.

\section{Acknowledgement}

This work was supported by the Maison des Sciences de L'Homme - Lorraine; and the Centre de Recherche sur les Médiations (CREM - EA 3476).

\footnotetext{
${ }^{1}$ This co-author has since moved affiliation and is currently a research fellow at University of Cologne (Germany).
} 


\title{
Networks as Culture:
}

\section{Understanding and accounting for risks within networks of medico-social actors}

word count abstract: 195

\begin{abstract}
The anthropological part of the present research project addresses the issue of risk and uncertainties relating to perinatality and disability, and draws from the discourses of professionals in a perinatal network in the French Lorraine region. From an anthropological point of view, it is necessary to determine how and to what extent the views of professionals determine the network's management policies. The place conferred to 'the user' in these representations is one of several important issues to be analysed in order to gain better understanding of the management of relationships that result from it. What is the position of professionals who 'negotiate' and 'organise' the cost of the risk of disability when grasped in connection with their images of the 'users' (children and parents)?

This qualitative study consisted of 40 semi-structured interviews conducted with 20 medical, social, and community professionals, all involved directly or indirectly with the network. The results demonstrate the importance of a network assessment as a 'culture' from the social and cultural relations of network professionals. These relations form the cement of a structure made of interpersonal ties and rooted in particular histories around a 'user' that are conveyed through individual narratives.
\end{abstract}




\section{Keywords}

perinatal network; risk assessment; disability; healthcare professionals; professional culture; France

word count main text (including references): 7768

\section{Introduction}

According to Sandre and Danesi (2007), the birth of very premature babies in neonatology wards brings up two essential questions for those in healthcare. The first pertains to the limits not to be exceeded in the healthcare provided and the second to the long-term future of babies who survive. Thus, in the framework of medical care for children who risk disability following their hospitalisation in the new-born intensive care unit (NICU), 'healthcare' needs to go further than simple medical 'monitoring' and yet existing procedures are essentially centred on the diagnosis of problems in these children. This diagnosis is associated with medical monitoring enabling healthcare to be improved through an enhanced knowledge of the symptoms involved. However, any holistic healthcare programme needs to integrate complementary points of view that respect all the dimensions of these developing human beings identified as being a 'population at high risk'. Any healthcare programme therefore essentially needs to be considered in the light of the various risks that could potentially handicap the future of the children concerned.

From this standpoint, monitoring risks for these children on a long-term basis involves other institutions than solely those in the medical sphere such as schools, medico-social establishments, the Réseau Périnatal Lorrain (Lorraine region Perinatal Network) and the RAFAEL network (Lorraine region Family Support Network). Insofar as the principal mission of a perinatal network is to ensure the security and quality of healthcare, risk as one feature of the network and thus of its culture is the main theme of this study on the overall care provided 
for the children concerned. For this, risk needs to be discussed from various points of view and understandings - those of the network's professional actors (subject of the present analysis) and of the families (subject of analyses by two psychologists from the NEORIS research project). Nevertheless, although the Perinatal Network exists as an institutional and legislative system, its actual implementation by different professional and community actors raises questions regarding coordination, information, decision-making and responsibility. How different logics, institutions, skills, organisations and spheres of activity can fit and work together also needs to be studied. Eventually, the aim of this paper is to highlight how three key features of the network - uncertainties and the way they are handled according to the actors, risk and the way it is perceived by the network's professionals, and users of the network and their roles they hold according to the network's professionals - come together to shape the network as culture.

A previous study (Arborio and Hascoët 2014) carried out in a neonatology department in the Lorraine region in France has shown the importance of carers' representations of risks by taking into account their uncertainties in the overall healthcare framework. The present study aims to reconsider these questions concerning the risks of disability in children based on the accounts of professionals from the Réseau Périnatal Lorrain. The analysis of their experience is of fundamental importance if we are to understand this kind of care both from a medical standpoint and on the social and cultural levels.

The notion of disability is complex as is demonstrated by the French Law of 11 February 2005 on the equality of opportunities, participation and citizenship for handicapped people, which gives a situational definition of disability. However, in a context in which this handicap may be uncertain because it is yet to be established, such a strict categorisation can make an approach to disability too rigid and neglect the complexity of the situation these children face. Thus, the question of the network professionals' uncertainties regarding a child's future must be an integral part of any study on the subject because it helps provide better understanding of how their views affect their assessment of a possible situation of handicap.

As well as the question of risk, this research based on taking into account professionals' 
uncertainties also aims for recognition of the immanent incompleteness of scientific knowledge. This incompleteness can be highlighted as an essential dynamic of organising acts through the informal aspects of caretaking. As Berthelot (2004) has stated, knowledge in HSS research is fundamentally mediation insofar as it translates the informal side of an institutional system based on the experience of those involved. The network's professionals manage risks partly on 'the basis of atomic information or attentive representations' (Berthelot, 2004:249), our translation) and partly within the framework of their own uncertainties as a reasoned formulation of their experience of the world. From that point, any knowledge that is uncertain always includes 'in its heart, the historicity of the world as it is jointly experienced' (Berthelot, 2004:249, our translation). Similarly, Memmi (2004) has shown to what extent, in the case of certain medical procedures pertaining to death, speech exchanges can act as behavioural controls. The author uses the phrase 'patchwork biopolitics' that, 'drawing on imaginations, unconsciouses, infralinguistic communication' (Memmi, 2004:150, our translation), act as an instance of insidious surveillance within the regulation of behaviours.

As well as the system itself, the network represents an inter-relational mesh requiring a singular positioning from actors vis-à-vis the other members, particularly through exchanges about their respective uncertainties. More specifically, the place given to 'users' (children and parents) in these representations is important for an analysis of the care relationships that develop from it. What is the position of the professionals who 'negotiate' and 'arrange' healthcare with the 'users' (parents)? How do professionals represent these 'users' (children) classified as being 'at risk of disability' when they leave the NICU? What role do their uncertainties play in the development of their image of these 'users' (parents and children)?

\section{Methodology}

From a methodological standpoint, this anthropological study highlights the subjective dimension of healthcare through a study of the professionals' views. The analysis of the relations between professionals who work directly or indirectly for the Réseau Périnatal Lorrain 
is based on a qualitative methodology involving semi-directive interviews. Forty interviews were carried out with twenty professionals taking part in the healthcare of the children with some integrated into the Réseau Périnatal Lorrain and the RAFAEL Network and some not (private practice and hospital doctors, coordinating doctors at the Réseau Périnatal Lorrain, the rectory and the PMI (French maternal and child welfare system), a GP, a gynaecologist; private nursery nurses and those working for the PMI and the Perinatal Network; private midwives and those working for the PMI, in liaison, or for the Perinatal Network; social workers; classroom assistants; a teaching advisor; a representative of the MDPH (Departmental Home for Disabled Persons); representatives of parents' organisations).

The objective of the NEORIS project as a whole is to better understand the modalities for healthcare effectively used in the perinatal field. From March 2010 and during 46 months, the work was carried out by a multidisciplinary team made up of a professor of medicine (J.M. Hascoët), three cognitive and clinical psychologists (A.M. Toniolo, H. Deforge, and L. Lotte), an anthropologist (S. Arborio), and a research assistant (J. Strzykala). An ANSM (Autorisation d'essai clinique ne portant pas sur un produit de santé nr. B121461-31; authorisation to perform clinical trials not involving a health product) and a CPP (Autorisation du Comité de Protection des Personnes nr. B121461-31; authorisation from the committee for the protection of persons) were obtained in February 2013. The anthropological data collection was carried out over a period of 8 months by one $\mathrm{PhD}$ student and research assistant in anthropology. Access to the field was granted and facilitated by the regional maternity unit, where she met with twenty professionals and asked them for informed consent to take part in anonymous interviews. Then, the main themes and categories of the gathered data were accessed and highlighted through discourse analysis by the project's principal investigator (anthropologist).

Despite the multidisciplinary team of the overall project and the different epistemological interests that go with it, this paper focuses on the anthropological gaze on notions such as narration, interpersonal relations, and culture, drawing upon methods of data collection and analysis traditional to the discipline. Ultimately, this paper aims to uncover views, positions, 
and the way they are articulated within a formalised network of actors involved with the care of vulnerable children.

\section{The risk of disability in children from a scientific and institutional standpoint}

\subsection{Perinatal networks in France: definition(s), context(s) and evolution(s)}

Neonatology refers to the birth environment of babies born in specific conditions. It is defined by the French Public Health Code as 'the surveillance and specialised care provided for newborn children who are at risk and those whose condition degenerates after birth' (JORF, 2005:37003). The reference population concerned includes children born prematurely or with a low birth weight, children with neurological pathologies or respiratory difficulties, and children who have had major surgery during the neonatal period and qualify as 'vulnerable' or 'fragile' (for the distinction between those labels see part 1.2.). Results of the EPIPAGE-2 study have shown that $0,44 \%$ of all births in France took place before 27 weeks, $0,87 \%$ between 27 and 31 weeks and 1,8\% between 32 and 34 weeks' gestation. After analysis, data from 2011 has shown that the more premature children are born, the more their survival rate decreases. Because preterm children are at high risk for neonatal, cerebral, respiratory and digestive complications in particular, survival rates without any type of severe neonatal pathologies are lower: they reach $97 \%$ at $32-34$ weeks, $81 \%$ at $27-31$ weeks, $30 \%$ at 25 weeks and $12 \%$ at 24 weeks' gestation (Ancel \& Goffinet, 2015).

However, as we will see in chapter 2.2., the population concerned by perinatal measures following an 'at risk' label in neonatology can differ according to the actors and professionals asked to define it and may extend beyond the original period defined for the field of neonatology. Perinatality may thus encompass the timeframe 'from the $28^{\text {th }}$ week of pregnancy to the $8^{\text {th }}$ day following birth and involves the health and survival of the fotus or new-born child' according to its scientific definition (CNRTL, 2016, our translation). For the purposes of perinatal networks for instance, perinatal care following the strictly medical period of neonatology extends up to the age of 8 . 
The results of research carried out in a neonatology department (Arborio and Hascoët, 2014) unequivocally demonstrate however that medical staff consider that a 'zero risk' situation cannot exist even though 'their analyses differ as to the importance to be accorded to this danger' (Carricaburu, 2007:125).

Consequently, although risks can be objectively evaluated medically, there is still a degree of uncertainty - that is to say doubt and unpredictability - inherent to the situation of perinatality. Furthermore, as Peretti-Watel (2011) points out, it is above all our relationship with danger that has changed, which leads us to reiterate the fact that risk is firstly a social construct and therefore that there are as many representations of a risk as there are cultural positions and social trajectories. In this way, the uncertainties of professionals in perinatal care are problematised in the melting pot of 'perceived' risks or, in other words, are constructed based on their respective experiences.

This paper aims to demonstrate that a sociocultural analysis of the network that goes further than the forms of rationalisation of healthcare is necessary, and also to show that this analysis reveals the uncertainties of the professionals while also giving them meaning in the framework of the effective implementation of this network.

In the interval of uncertainty relative to the risks of after-effects, there is the question of the responsibility of carers with regard to the healthcare offered to children and their families (see also Arborio and Hascoët, 2014), highlighting how new modes of functioning in neonatology, including the notion of a network, have led to the development of ethical questions linked to the child, the family, life and death. The 'health network' concept derives from the importation of Anglo-Saxon organisation models. In fact, according to the French Public Health Code, 'the purpose of health networks is to promote the access to healthcare and the coordination, the continuity or interdisciplinarity of healthcare, particularly when it is specific to certain populations, pathologies or health activities' (our translation). The health network is an 
innovative mode of organisation for health services initially viewed as a means of controlling spending in this area and now considered an essential tool for improving practices. According to their objectives and working area, networks implement actions linked to prevention, education, care and health and social monitoring (Art. L6321-1 and L6321-2, French Public Health Code).

Like all networks of this type, the Réseau Périnatal Lorrain built a network to monitor and care for 'vulnerable' children (RAFAEL). It provides children who are 'presumed to be at a major risk of deficiencies that are a source of disability' with systematic, official care support involving 'attentive surveillance of development in all its dimensions (motor, sensorial, cognitive, intellectual, emotional and psychological)' (Réseau Périnatal Lorrain website, 2016). More specifically, the Réseau Périnatal Lorrain has been constructed locally based on the experiences of carers in their respective institutions (Arborio and Hascoët, 2014). The main objective of support networks for 'vulnerable' children (see also INSERM \& Larroque, 2000; INSERM, 2004) is to detect developmental anomalies as early as possible and thus provide such children with the right healthcare as close as possible to the family home, to reduce the consequences of possible disabilities or limitations that are detected and thus avoid secondary disability or an 'over-handicap'. The network concept refers to a mode of care and support whose coordination function is its main specific feature, thus illustrating collaborative work involving independent structures including maternity wards, private doctors, the PMI system, care structures, school health services, etc.

\subsection{The multidimensional question of the risk of disability}

The public health system considers risks linked to premature birth in terms of the vital prognosis, psychomotor development and from the standpoint of both the child and the parental entourage in the overall perspective of 'well-being' associated with health. Medical risks in this area are sometimes considered independently from their social, economic, familial and cultural contexts. They thus concern children coming from the neonatology sphere in a homogeneous fashion based on categories determined from a medical standpoint only. If this homogeneous 
and objective approach is called into question, then all predictions of after-effects need to integrate a plurality of risk factors. Firstly, on the medical level, the children's development shows that there is a great deal of variation in the presence or, if applicable, the form of aftereffects encountered particularly when no serious pathologies have been diagnosed during the hospitalisation period. Secondly, the notion of vulnerability combines with the notion of risk under the common name of 'fragility' associated with a state of health perceived as such in its later development. In itself, the notion of risk cannot be grasped independently from its classificatory connotation. This categorisation accentuates even stronger here as the idea of 'vulnerability' goes beyond medical objectivity and reaches a more commonly social sense. 'Classifying' a child as 'vulnerable' inconveniently tends to stigmatise the subject and thus to increase the risk of a social handicap. Indeed, the situation of disability has a broader context involving the social participation of the individual and their quality of life as well as of their entourage (see also Barreyre, 2000).

While the acceptance of handicap is situational in nature, the notion of prevention has a different meaning and this all the more so when this situation needs to be evaluated based on what we mean by 'risk of disability' and not on a recognised disability. However, how can the norm be assessed in the event of uncertainty?

For professionals, risk needs to be considered in priority with regard to the child whose quality of life requires assessment throughout their development but also with regard to the parents whose legitimate concerns about the health of their child may conflict with other imperatives.

Here, our reflections focus on the aspect of uncertainty among professionals and much less on the parents or the child. Indeed, a CSTS (French superior council for social work) report says that 'resorting to notions of situation or social development means departing from the watchword: 'putting users at the heart of the system" (CSTS \& Jaeger, 2015:135, our translation). However, does the 'target' user, as we may consider the 'at risk' child, not primarily exist through this paradoxical tension between the necessity for professionals to inform parents, and their own uncertainties inherent to the evaluation of a situation that has yet 
to occur? And in this case, should we not consider their uncertainties as organising principles for social relationships rather than elements against which scientific knowledge and the healthcare that derives from it need to protect?

\section{The social and cultural dimensions of the network}

\subsection{Re-problematising the assessment of the perinatal network}

Assessing networks is an essential objective linked to initial preoccupations regarding the quality of the health system (Public Health Law dated 4 March 2002).

The ideas provided in response to this concern involved an evaluation of the 'effective system' of the network and its institutional logics (service and provision) before any considerations on interactions between the different partners. In reality, 'the evaluation of the networks should be understood as an assessment of the extent to which qualitative and quantitative objectives are met, thus enabling a measurement of the networks' impact on the quality of the care provided for patients, of health professionals and of the network's healthcare environment' (Bourret, 2010:83).

The remark of an actor from the Réseau Périnatal Lorrain testifies to this idea:

'It's true that it's really a permanent feature to evaluate what we do, perinatal policies and surgery, evaluating... what becomes of these children' (coordinating doctor)

Furthermore, the same law also stresses the importance of patients' rights through the system's 'democratic' dimension. If, as Maudet (2002) points out, the user is situated in the more general framework 'of a public action which affects all sectors of society (social, political, health), namely that of participative democracy and the demands of the partnerships and deliberation 
between the actors concerned', then any assessment of a network needs to also take into account the place of 'the user' within the system. This notion of a stigmatising nature is being currently criticised to the point that it has become the title of the CSTS report (2015) 'Please stop calling us user':

'more and more people who are directly concerned as well as associations ask that the term 'user' be no longer used because it evokes ideas like: used, subjugated, helpless, etc.' (CSTS, 2015:22, our translation)

However, the use of the term 'user' in the medico-social field produces confusion in professionals' representations between the terms of 'user' and 'patient' whereas a child 'at risk' of disability is not necessarily ill or even in a situation of handicap.

Hence, the anthropological section of the NEORIS project aims to shed light on the notion of 'user' viewed here in the framework of its relations. The study of the professionals' views on the network turns out to be a prime observatory determining the singular characteristics of their social links around their own conception of 'the user'.

Particular attention was paid to communication within the networks for two reasons. Firstly because of the subject of the study itself - interpersonal relationships based around uncertainties linked to the conception of 'the user', and secondly because the communication of formal and informal information is an essential preoccupation for the network's medical and social staff. Some, including authors from the field of communication and information, have realised the importance of defining healthcare democracy as 'a construction of trust between all the partners involved' (Bourret, 2010:80) that, among other aspects, builds upon linguistic interactions. 
However, strictly speaking few studies in anthropology have covered the communicational aspects of networks (on the link between action and language, see Winkin, 1996).

\subsection{Contextualising assessment: a cultural approach to networks}

This approach to network is part of the sociometric tradition that 'uses the concept of the network to describe a residual category of social relations based neither on territory nor on occupations but instead on family relationships, friendship and social class. (...) It enables the representation of social relations between the members of the same network' (Quentin, 2012, our translation).

Considered on a cultural basis, assessing a network thus consists of contextualising the actions of professionals based on a structural understanding of the network and the interpersonal situations involving statements and decision-making. The notion of culture is inherent to all social organisations and is in fact based on 'questions of links, meaning, knowledge and action' which make networks 'organisations between plans and accounts that are given' (Bourret, 2010:79, our translation) with all the importance of speech acts (Gramaccia, 2001, our translation). This cultural approach of the network appears in de Certeau's work on 'the act of speaking':

'It operates in the field of a linguistic system; it brings into play appropriation or reappropriation of language by the speakers; it installs a present relative to a moment or a place; and it seals a contract with the other (the interlocutor) within a network of places and relations' (de Certeau, 1990:XXXVIII-XXXIX, our translation). 
In itself, culture allows for social relations that make it up to be 'comprehended in act', and discursive exchanges attest to their main characteristics: within an interactionist framework, creative as expressions of individual singularities, and interpretive as translations of aporetic meaning. Here, culture is to be understood as 'passing', as is the network, for which the definition we draw upon is Latour's of a 'translation' of the contingency of reality by its actors: the theory of the actor-network positions the actor in a web of relations that connect heterogeneous entities, that is to say in an active (as opposed to fixed) sociotechnical network (Akrich, Callon \& Latour, 2006).

The interest of approaching risk through uncertainties lies in the approach itself: here, it is less about characterising a concept than about analysing its elaboration and its sharing between actors through the figure of the user.

Thus, beyond the objective approach, a network needs to be evaluated in a dynamic manner as 'a set of interconnections whose configuration is in a state of permanent evolution' (Dugnat, 2012:139, our translation). A network is grounded in coordination and implies that each subject which makes it up 'is defined by the relations he/she has with other people' (Dugnat, 2012:140, our translation). Consequently, the approach to evaluation needs to be dual in nature and cover both the dynamics and the system to favour the articulation between logics of cooperation and compliance with norms.

\section{From coordination...}

Perception of the risk of handicap is part of perinatality Outside the very precise medical period defined in chapter 1.1, the risk of handicap is the subject of broader surveillance particularly when the children involved have been hospitalised in NICU. In the framework of the Réseau Périnatal Lorrain and more specifically the RAFAEL network, this surveillance carries on to the age of 8 following a pre-defined schedule. 
According to a regional coordinating doctor in the PMI system, 'the user's health file is used to organise the links between the system's professionals and helps anticipate all possible risks'. Here, coordination is based on precise criteria which are 'well-defined and identified and on which our professionals direct their interventions and create links with each other in a wellstructured scheme'. From this standpoint, the idea is to objectify risk and evaluate how it is managed and how care is provided:

'The tendency is more 'let's objectify what is done' to be able to give an account of what exists because while things remain informal, it is difficult to make an evaluation using classic criteria involving the provision of services because that would be merely giving an account' (regional coordinating doctor in the PMI system).

... to cooperation.

Nevertheless, in-depth interviews with the network's actors reveal that this structural approach to risk management does not reflect the entire reality of how such care management is actually implemented.

'The informal nature of relations means that many things spill over from this case file' (regional coordinating doctor in the PMI system). 
Indeed, the implementation of monitoring can also be based on the cooperation between professionals, the modalities of which can take on more implicit and interpersonal forms that cannot be grasped by an objective assessment. Callon noted that 'trust is involved as a coordination modality between the members of the network beyond organisational and hierarchical coordination' (Callon, 1991:198 cited in Bejean and Gadreau, 1996:84, our translation).

Ultimately, it seems in this context that the objective value of risk is not sufficient to determine the modalities of healthcare provision for the child. The actual subject of people's preoccupations, namely the 'risk of handicap in children' requires particular attention, which makes it easier to understand the professionals' position. As a doctor from the Perinatal Network precisely describes:

'it's a link... the very nature of specialists means that it's a lot about an area of health dealing with really small children and that means there's a lot of anxiety. There's a real burden in what a risk of handicap represents, it's massive for a family, it can't be dealt with in a purely objective manner. I think that professionals need to know each other, you can't just refer a baby, a mum, it's almost impossible (regional coordinating doctor in the PMI system).

\subsection{An atmosphere of cooperation?}

Information systems and shared digital medical files are part of the coordination of actions but cooperation implies a relational dimension linking the actors involved in care provision. Therefore, it is necessary to make a distinction between the respective definitions of 
cooperation and coordination. The latter corresponds to the harmonisation (see also Instruction $\mathrm{N}^{\circ}$ DGOS) of various services, forces and components to enhance effectiveness. Cooperation however requires a certain harmony between all the members of a group with a view to achieving a common goal (CNRTL, 2016, our translation). A PMI doctor confirms that: 'I think we need to get away from the idea that a network can be made up of institutional elements. For professionals, the institutional sphere manages axes and provides tools and means but (...) I think that these are interindividual links, being introduced, introducing yourself and what makes up real work in a network is people knowing each other'.

This opinion is also shared by the social worker from a maternity ward that is part of the network: 'I have the impression that it depends on people rather than on the position they hold'. This kind of interpersonal dynamic is also present in observed dysfunctions: 'If things don't go well, I think it's more a question of affinity between professionals or people' (former coordinating nursery nurse in the PMI system).

Consequently, cooperation is supported by the biographies of those involved woven together gradually by interpersonal relationships, which is not necessarily the case with coordination. In this, healthcare 'democracy' would be in a context of singular enunciation. Yet, a situation is based on the meaning actors give to it beyond any pre-established definitions. Meaning is constantly renewed in the framework of interpersonal relationships and thus needs to be approached according to both local characteristics (the temporal, spatial, and social frameworks) and the interactions that make up the situation.

Therefore, assessments of the network need to be resituated in a collective history situated locally and shared by the actors who make up the network. This informal dynamic forms 'niches' of efficiency helping actors get around the slow sides of a formal coordination system which, while initially set up to deal with emergencies, sometimes becomes counterproductive: 
'After a child is born, there are a lot of urgent administrative procedures to be done and then there's the paperwork and so there can be a delay of a few weeks which can be harmful. (...) It was officially stated that liaisons should be enriched (...) but I also think that I was lucky enough to know people and be warned a little earlier or at least to speak on the phone which isn't always the case' (former coordinating PMI nursery nurse).

Evaluating the network thus means looking at the common culture linking individuals. In this way, the network becomes a true 'social action' as Duranti (1994) understood it - an everevolving social system formed of a variety of codes which accepts multiple, socially distributed representations. This highlights the importance of an assessment starting with the social and cultural context that makes up the network.

'It is more a case of the history of events leading us to move from an informal to a formalised situation' (regional coordinating doctor in the PMI system).

However, the network organises itself on interrelations between the professionals themselves and with the users, which means that only an analysis of their views would enable better understanding of the terms of their effective cooperation. 


\section{The network: Cultural patchworks of a 'user'?}

In what terms may we speak of a healthcare democracy? If we are to stress the importance of bringing together the different partners in the field of early childhood within networks and the interest of promoting the development of a common culture, the contextual analysis of networks requires us to think about the 'know-hows' of the field of perinatality.

\subsection{Accounts told about perinatality: at the interface of various expertise...}

The field of perinatal care has evolved over the last 20 years with this rather medically-centred sphere opening up to questions of overall health in which the approach to children is not isolated, but rather integrated into their family context. From 1992 onwards in the USA, the founding principles of care centred on the family have been clearly stated (Harrison, 1993). In a resuscitation unit, it needs to be possible for parents to be involved in nursing care if they feel capable to do so to minimise the effects of the interruption of the pregnancy progress in the event of a premature birth. More recently, the emergence of the notion of an 'expert patient' correlates with the idea of an 'expert parent' in the perinatal field with the added perspective of a child being 'in development' rather than 'in gestation'. This conceptual shift means that 'risk' then has a less medicalised nature and is the subject of apprehension shared between parental, medical, and social expertise.

A child's development is thus an integral part of their family history, which means the family doctor needs to be involved in healthcare monitoring. On this subject, the opinion of one interviewed GP contrasts with that of paediatricians who, 'in principle are not a part of the parents' history whereas you need to find out what's been prepared beforehand and the way things will be looked after subsequently' (GP, city of Nancy).

Furthermore, when parents in neonatology are referred to a paediatrician or a GP for the ongoing care of their child, this amounts to an ambivalent representation of risk. This is because 
GPs make decisions depending on an absence of illness whereas paediatricians or the hospital would get involved in the event of an illness. However, in the case of children supposed to be 'vulnerable' or 'fragile', how is it possible to specify their exact condition and refer them for appropriate healthcare? Would that condition require specialised or generalist medicine which for this GP amounts to asking 'is the child in good health?' and thus needs primary healthcare or is the child 'ill' and thus needs specialised care?

Once a pregnancy is underway, risks will be determined on the basis of preconceived criteria such as a late notification of pregnancy, a refusal to be involved with the PMI system, reluctance in accepting regular monitoring, a minor or isolated woman, a single parent. More precisely, 'at risk' groups are identified by 'specific characteristics' (Faya-Robles, 2014:6, our translation) which also leads to the distinction of 'low' and 'high' risk pregnancies. In certain cases, the social nature of these criteria is associated with medical aspects like pregnancy in later life or drug/alcohol addiction, which make risk the vector for 'prejudices about pregnant women considered to be 'deviant'' (Faya-Robles, 2014:1, our translation). At this level of evaluation and understanding, 'the risk factor par excellence is lifestyle' (Faya-Robles, 2014:9, our translation) and risk acts as a cultural resource through which the public health system attempts to impose norms for suitable behaviour' (Faya-Robles, 2014:9, our translation).

This initial categorisation phase in prenatal care involves 'at risk mothers' (Faya-Robles, 2014:8) and extends to 'at risk children' through the use of common terms marked by the notion of "fragility". Throughout the realm of parenthood, there is a question of moral control of the 'mothers or parents - children' relations.

'Before, we used to concentrate more on the medical side whereas today we look at parenthood in more depth" (PMI midwife). 
Some professionals deplore the lack of commitment from parents in attending consultations in the framework of the RAFAEL network. Conversely, others can see the effects of this implicit moralisation on the trust of parents and go beyond the call of duty to work on developing a durable cooperation relationship with them.

'Between the PMI midwives and the mothers, before there were job cuts(...) the midwife was viewed differently from someone who controls things; she is a 'resource' person, well also... a woman who can understand another woman's problem ...' (Social worker within one of the network's maternity wards)

Moreover, this indicative categorisation can also produce differences between the written form of a case file and life as it is actually lived in family situations. As one social worker put it: 'There are children who aren't in any of the categories so we're going to refuse them and the parents will find it really hard to find something that suits them' (Social worker, city of Nancy). What these professionals' statements show is that in addition to the necessity for every one of them to balance and navigate uncertainties when it comes to defining risks, ensuring the monitoring of these risks, and predicting possible future needs, they also report the necessity to enable meaningful connections with other experts in order to create a network around the atrisk child despite a possible lack of protocol, of clear procedure, as well as of resources to go beyond their specific purview. 


\subsection{Risk and trust: from control to lived experience}

According to Bejean and Gadreau, 'the network is no longer based on trading relations or on authority-based relations occurring within the hierarchy. Now there are relations of trust, informal relations (based on neighbourhoods, circles of people who know each other, teams, etc.) which characterise the networks' (Bejean and Gadreau, 1997:84, our translation). Even though this observation has been nuanced in the framework of sociology of (social) networks, it allows us here to specifically illustrate part of the findings of our study pertaining to the importance of relations of trust between the actors of the perinatal network.

In particular, the approach to risk in the framework of relations based on trust requires that time be made essential data for analysis. Time represents both a sine qua non condition for interpersonal relationships based on trust and also the medium for the progressive experience on which the approach to risk is based. When a handicap is diagnosed, time acts a cement for the interface of the relations making up the health monitoring provided for the child: ' $I t$ 's $a$ question of time, in certain situations, it's really time that does the work (...) Meanwhile, it's our job to be available for the parents and their questions and requirements' (teaching advisor). This longitudinal approach to risk can nonetheless be hampered by logics of compartmentalised medical specialities: 'Overall, I don't have anything to do with postnatal matters. I don't have a role in paediatrics either. I'm not close enough to the actual birth to take part in it' (gynaecologist, city of Nancy). On the contrary, perinatality should be resituated in the life path of a specific child which may be interspersed with uncertainties, the meanings of which need to be shared between professionals. For example, professionals' views on the seriousness of a situation may differ and only a collective exchange regarding the child's history then enables enlightened assessment: 
'Doctors and nursery nurses can often evaluate the seriousness of a situation completely differently which is why it is a good idea to work together' (regional coordinating doctor in the PMI system).

Thus, managing risk needs to go further than providing care and the right referrals. It clearly requires the actors to cooperate, providing a basis for the meanings attributed to risk to be collectively developed and shared and responsibilities assumed. This approach seems of even more fundamental importance in an area in which risk can only be 'considered' and uncertainties remain despite existing indicators.

'[Risk] is extremely difficult to categorise in the field we work in; in neonatology, the word 'risk' is not actually written on the child's forehead when it gets discharged or three days later and sometimes we get some big surprises' (PMI departmental coordinating doctor).

Here, accounts given seem like an elementary form of discourse facilitated by certain figures within the network. For example, PMI midwives are considered 'relays for trust' (regional coordinating doctor in the PMI system) and provide a link between the medical sphere and the child's family.

This account of the narrative, historicised form of the child's medical history also exists in the school framework where diagnosis is not an actual prime subject of interest: 'We talk about developmental delay or acquisition delay but whether the child is premature or not doesn't really matter; so then... it's the child's life story and we obviously take that into account' 
(teaching advisor). This shift from medical categorisation towards a subject's history represents the move from a public form of diagnosis involving medical secrecy and categorisation to a 'private' form of a 'handicap situation' revealed in the context of a personalised account. In particular, a user's trust invested in whichever actor must be preserved beyond the diversity of actors involved. These actors are individuals who are part of a collective story underpinning the dynamics of links within a network of confirmed effectiveness: 'if the trust of users is respected and they are at the centre of the process, then we can call this a personalised network experience' (Roegiers, 2015:42, our translation).

\section{Conclusion}

If, as Bruyère underlines, 'each network is by definition labile' (Bruyère, 2004:121, our translation) then a standardised assessment thereof would involve a risk of rigidifying potentialities. This paper has demonstrated that a contextualised assessment of networks is of positive value with those networks are approached as 'cultures' and not solely as structural care systems. It showcases the importance of what is said when it comes to grasping and managing risk in the framework of a network of perinatal care. It does not intend to analyse the uses themselves outside of their discursive reality. This albeit partial choice is of interest when it comes to mobilising the reader's attention on the performative character of narration within the historicisation of the figure of the user, thus moving away from the conventional discrepancies between 'what is said' and 'what is done' and towards - at least for now - a reflection on experiences.

To show this, we have stressed the interpersonal dynamics implemented by professionals to manage the risk of handicap in children including the integration of the uncertainties inherent to such a situation. Finally, we have shown that the relations between those involved are based on a narrative, historicised form of social link and built upon the transmission of meanings, knowledge and action.

This kind of approach based on interpersonal links also requires thought about the place of 'the at-risk user' as defined in the views of the professionals. It is even more important to re- 
contextualise the place occupied because an approach to risk on the basis of preconceived indicators associated with the categorisation of 'vulnerability' takes the child out of their specific personal history. And yet, this kind of approach presents the danger of 'healthification' as referred to by Fassin (2000), namely 'the translation of several social problems into health terms but also the introduction of new regulatory systems' (Faya-Robles, 2014:3, our translation). The latter author shows the 'different uses of the notion of risk and the institutional configurations which use it to regulate behaviour' (Faya-Robles, 2014:3, our translation). Even if, to some extent, the emergency of certain risky situations demands to control the behaviours of individuals beyond the remit of medicine, this observation once made allows for limitations to become apparent. In particular, this paper shows that in the framework of perinatal networks, monitoring risks cannot be the sole means to connect medical procedures with societal behaviours in the sense that the latter pertain to much more informal dynamics such as the development of interpersonal ties of trust.

However, the implicit regulation of parental behaviour limits the autonomy of users which is an aspect of fundamental importance in the (re)construction of the link with the child in hospital. As Roegiers makes clear, 'the autonomy of the user is not promoted although it is essential for the transition towards parenthood (Roegiers, 2015:42, our translation).

Consequently, it seems essential to give 'users' back their 'public' dimension involving sharing ideas and experiences, which means putting them back in the context of exchange. From this standpoint, the 'at-risk user' cannot be viewed as an isolated entity - even less so in the case of new-born babies - and needs to be considered as an 'individual with many social relationships, who is constructed as such by placing themself at the centre of a network of significant relations' (Faya-Robles, 2014:17, our translation) which includes those constructed with healthcare and other professionals. 


\section{References}

Arborio, S. and Hascoët, J.M. 2014. "La gestion du risque par les soignants en situation de prématurité.” Revue Sociologie Santé, 37, 195-215

Akrich, M., Callon, M. and Latour, B. eds. 2006. Sociologie de la traduction : textes

fondateurs. Paris : Mines ParisTech, les Presses « Sciences sociales ».

Ancel, P.-Y. and Goffinet, F. 2015. "Survival and Morbidity of Preterm Children Born at 22 Through 34 Weeks' Gestation in France in 2011." JAMA Pedriatics, 169(3), 230-238.

Barreyre, J.-Y. 2000. Classer les exclus, enjeux d'une doctrine de politique sociale. Paris: Dunod.

Bejean, S. and Gadreau, M. 1997. "Concept de réseau et analyse des mutations récentes du système de santé." Revue d'économie industrielle, 81(3), 77-87.

Berthelot, J.M. 2004 (1996). Les vertus de l'incertitude. Le travail de l'analyse dans les sciences sociales. Paris: Presses Universitaires de France.

Bourret, C. 2010. "Évaluation et communication des nouvelles organisations d'interface : le cas des réseaux de santé.“ Communication et organisation (online), 38. Available at http://communicationorganisation.revues.org/1411 (last accessed November 16th, 2016).

Bruyère, C. 2014. Les réseaux médico-sociaux : quels sont les leviers de la coordination des connaissances? (unpublished Master's thesis). Université de la Méditerranée (Aix-Marseille 
II), Faculty of Economics and Management Sciences, Research Center for Transports and Logistics.

Certificate of Further Education thesis (Logistics and Organisations Management)

Bulletin épidémiologique hebdomadaire (BEH) 24 November 2009, 44-45. Available at the Institut de veille sanitaire (INVS) website :

http://invs.santepubliquefrance.fr//display/?doc=beh/index.html (last accessed November 21st, 2016).

Carricaburu, D. 2007. “De l'incertitude de la naissance au risque obstétrical : les enjeux d'une définition." Sociologie et Sociétés, Revue de l’Université de Montréal, XXXIX(I), 123-144.

Centre national des ressources textuelles et lexicales. http://cnrtl.fr/definition/périnatalité (last accessed November 21st, 2016).

Centre national des ressources textuelles et lexicales. http://cnrtl.fr/definition/coordination (last accessed November 21st, 2016).

Code de la Santé Publique (French Public Health code) Articles L6321-1 and L6321-2 C. Available at https://www.legifrance.gouv.fr/affichCodeArticle.do;jsessionid=C0952EA74D9207B1B8778 $\underline{\text { FDB9DEFAF59.tpdila07v } 3 \text { ? cidTexte=LEGITEXT000006072665\&idArticle }=\text { LEGIARTI00 }}$

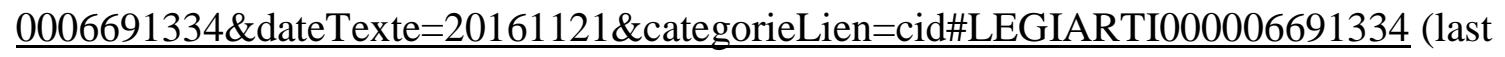
accessed November $21^{\text {st }}$, 2016).

Conseil Supérieur du Travail Social (French superior council for social work) (CSTS). 2015. Refonder le rapport aux personnes - Merci de ne plus nous appeler usager. Available at 
$\underline{\text { http://social- }}$

sante.gouv.fr/IMG/pdf/CAB_COM_RAPPORT_COMPLET_Merci_non_usagers.pdf (last accessed November 21st, 2016).

Conseil Supérieur du Travail Social (French superior council for social work) (CSTS) \& Jaeger, M. 2015. Place des usagers. Available at http://socialsante.gouv.fr/IMG/pdf/Placedesusagers.pdf (last accessed November 21st, 2016).

de Certeau, M. 1990. L’invention du quotidien - arts de faire. Paris: Folio Gallimard.

Dugnat, M. 2012. "Réseaux en périnatalité : les outils pratiques d'une prévention universelle prévenante ? Définitions, critiques et propositions." Spirale, 61, 139-162.

Duranti, A. 1994. From Grammar to Politics: Linguistic Anthropology in a Western Samoan Village. Berkeley/Los Angeles, CA: University of California Press.

Fassin, D. 2000. “Entre politiques de la vie et politiques du vivant. Pour une anthropologie de la santé." Anthropologie et Sociétés, 24(1), 95-116.

Faya-Robles, A. 2014. "Régulations en santé materno-infantile en milieu populaire à partir de la notion de risque. " Anthropologie \& Santé, 2014(9). Available at http://anthropologiesante.revues.org/1525 (last accessed November 21st, 2016).

Gramaccia, G. 2001. Les actes de langage dans les organisations. Paris: L'Harmattan.

Harrison, H. 1993. “The principles for family-centered neonatal care.” Pediatrics, 92, 643650. 
Institut national de la santé et de la recherche médicale (French national research institute for health and medical research) (INSERM) \& Larroque, B. 2000. Enquête EPIPAGE (EPIdémiologie des Petits Ages Gestationnels). Available at https://epipage2.inserm.fr/index.php/fr/cote-recherche/publications-scientifiques (last accessed November 21st, 2016).

Institut national de la santé et de la recherche médicale (French national research institute for health and medical research) (INSERM) 2004. Déficiences ou handicaps d'origine périnatale. Dépistage et prise en charge. Expertise collective de l'Inserm. Available at www.inserm.fr/content/download/7158/55269/.../1/.../déficiences+et+handicaps.pdf (last accessed November $\left.21^{\text {st }}, 2016\right)$.

Journal Officiel de la République Française (Official journal of the Republic of France) (JORF) nr.172 dated July $26^{\text {th }} 2005$, page 37003 , text nr. 101, decree nr. 2005-840 dated July $20^{\text {th }} 2005$ relative to the sixth part (Regulations) of the French Public Health Code and modifying certain regulations set out in this code.

Liaw, F.R. and Brooks-Gunn J. 1994. "Cumulative familial risk and low-birthweight children's cognitive and behavioral development." Journal of Clinical Child Psychology, 23(4), 360-372.

Maudet, G. 2002. "La « démocratie sanitaire » : penser et construire 1'usager" Lien Social et Politiques, 48, 95-102. 
Memmi, D. 2004. Administrer une matière sensible. Conduites raisonnables et pédagogie par corps autour de la naissance et de la mort. In Fassin, D. and Memmi, D. eds. Le gouvernement des corps. Paris: EHESS, 135-154.

Ministère des affaires sociales, de la santé et des droits des femmes (French Ministry of social matters, health and womens' rights) 2015. Instruction $\mathrm{N}^{\circ} \mathrm{DGOS} / \mathrm{PF} 3 / \mathrm{R} 3 / \mathrm{DGS} / \mathrm{MC} 1 / 2015 / 227$ du 3 juillet 2015 relative à l'actualisation et à l'harmonisation des missions des réseaux de santé en périnatalité dans un cadre régional. Available at http://circulaire.legifrance.gouv.fr/pdf/2015/07/cir_39846.pdf (last accessed November 21st, 2016).

Peretti-Wattel, P. 2001. La société du risque. Paris: La Découverte.

Quentin, I. https://isabellequentin.wordpress.com/2012/03/29/sens-et-etymologie-du-motreseau/ (last accessed November 21st, 2016).

Réseau Périnatal Lorrain. http://www.reseauperinatallorrain.fr (last accessed November 21st, 2016).

Roegiers, L. 2015. 'D'une culture de réseau à l'émergence d'une formation belge en réseau." Spirale, 61, 37-46.

Sandre, D. and Danesi, N. 2007. Réanimation néonatale : le bébé et ses parents entre ruptures et liens : Le travail préventif du binôme pédiatre-psychanalyste. In Grosclaude, M. ed. L'enfant réanimé. Paris: ERES, 159-206.

Winkin, Y. 1996. Anthropologie de la communication, de la théorie au terrain. Bruxelles: De 
Boeck Université. 